\title{
1 Cryptic lineages of a common alpine mayfly show strong life history divergence
}

2 Marie Leys ${ }^{1,2}$, Irene Keller ${ }^{3}$, Christopher T. Robinson ${ }^{1,2}$ and Katja Räsänen ${ }^{1,2}$

$3^{1}$ Department of Aquatic Ecology, EAWAG, Swiss Federal Institute of Aquatic Science and 4Technology, Ueberlandstrasse 133, 8600 Dübendorf, Switzerland

5²Institute of Integrative Biology, ETH-Zürich, 8092 Zürich, Switzerland

$6^{3}$ Department of Clinical Research, University of Bern and Swiss Institute of Bioinformatics, 73010 Bern, Switzerland

8*Corresponding author: Marie Leys (marie.leys@eawag.ch)

9Running title: life history divergence of Baetis alpinus cryptic lineages

10

This document is the accepted manuscript version of the following article:

Leys, M., Keller, I., Robinson, C. T., \& Räsänen, K. (2017). Cryptic 1ineages of a common alpine mayfly show strong life-history divergence. Molecular Ecology, 26(6), 1670-1686. https://doi.org/10.1111/mec.14026 


\section{ABSTRACT}

12Understanding ecological divergence of morphologically similar but genetically distinct 13species - previously considered as a single morphospecies - is of key importance in 14evolutionary ecology and conservation biology. Despite their morphological similarity, 15 cryptic species may have evolved distinct adaptations. If such ecological divergence is 16unaccounted for, any predictions about their responses to environmental change and 17biodiversity loss may be biased. We used spatio-temporally replicated field surveys of larval 18cohort structure and population genetic analyses (using nuclear microsatellite markers) to test 19for life history divergence between two cryptic lineages of the alpine mayfly Baetis alpinus in 20the Swiss Alps. We found that the more widespread and abundant cryptic lineage represents a

21 'generalist' with at least two cohorts per year, whereas the less abundant lineage is restricted to 22higher elevations and represents a 'specialist' with a single cohort per year. Importantly, our 23results indicate partial temporal segregation in reproductive periods between these lineages, 24potentially facilitating local coexistence and reproductive isolation. Taken together, our 25findings emphasize the need for a taxonomic revision: widespread and apparently generalist 26morphospecies can hide cryptic lineages with much narrower ecological niches and 27distribution ranges.

28keywords: Baetis alpinus, voltinism, cohort, sympatry, population genetic structure, 29 morphospecies 


\section{INTRODUCTION}

32How biological diversity emerges and evolves is a key question in evolutionary and 33conservation biology (Schluter 2001; Seehausen 2009). An important prerequisite to infer 34evolutionary and ecological processes in natural populations is the appropriate definition of 35evolutionarily distinct units (Crandall et al. 2000). One clear challenge in this endeavor is 36posed by cryptic species, which are morphologically similar, yet reproductively isolated and 37genetically distinct (Bickford et al. 2007). Cryptic species diversity has become increasingly 38apparent due to the advent of molecular techniques, and suggests that existing criteria and 39practices of species identification are often insufficient (Pfenninger \& Schwenk 2007; Jörger 40\& Schrödl 2013). As a primary concern, the presence of cryptic species leads to an 4lunderestimation of biological diversity (Scheffers et al. 2012; Adams et al. 2014). 42Furthermore, cryptic species can be specialized in their ecology - increasing the risk of 43species loss under environmental change (e.g., Pauls et al. 2013; Feckler et al. 2014). Beyond 44these important implications for conservation, cryptic species also challenge our 45understanding of population connectivity (Pante et al. 2015), speciation, and even ecosystem 46functioning (Seehausen 2009 ; Brodersen \& Seehausen 2014).

47If well-recognized species consist of multiple ecologically divergent lineages, any apparently 48wide ecological niche and strong life history plasticity may actually reflect genetically distinct 49specialists (similar to the concept of individual specialization within generalist species, 50Bolnick et al. 2003). Furthermore, co-occurrence of morphologically similar species raises 51questions about mechanisms that facilitate divergence and allow species coexistence. For 52 instance, stable coexistence of similar species is thought to require some form of ecological 53segregation (i.e., resources, space, or time, Mac Arthur \& Levins 1964; Armstrong \& 54McGehee 1980; Carothers \& Jaksic 1984; Chesson 2000). Such segregation may arise 
55through divergence in life history strategies, favoring one or the other competitor under 56different spatially or temporally varying environmental conditions (Qvarnström et al. 2005; 57Qvarnström et al. 2009).

58At high latitudes or altitudes, seasonally divergent selection may act on the timing of life 59history transitions (Roff 1983; Stearns 1992; Danks 1994; Nylin et al. 1995). An 60understanding of how such seasonally divergent selection affects reproduction, population 61dynamics, and genetic divergence on life history traits is crucial in the context of climate 62change (e.g., Kivelä et al. 2013). In cryptic species, knowledge about life history divergence 63across environmental mosaics can furthermore provide insight into drivers of adaptive 64divergence and mechanisms of species coexistence.

65Stream invertebrates provide a well-suited study system for testing life history divergence of 66cryptic species. First, as ectotherms, freshwater invertebrates strongly respond to variation in 67 temperature and season length. They adjust the timing of their growth period, the number of 68generations produced within a year (i.e., voltinism) and their developmental pathways (e.g., 69diapause vs. direct development, Masaki 1978; Sweeney 1978). Second, cryptic diversity is 70common in various stream invertebrates (Jackson et al. 2014), including baetid mayflies 71(Ephemeroptera) (e.g., Williams et al. 2006; Pereira-da-Conceicoa et al. 2012; Gill et al. 722016). Recent work on the alpine mayfly Baetis alpinus (Pictet) - a widely distributed and 73phenotypically plastic species (Humpesch 1979; Lavandier 1988; Breitenmoser-Würsten \& 74Sartori 1995; Kukula 1997; Erba et al. 2003; López-Rodríguez et al. 2008) - indicates that 75this species is a composite of at least two genetically distinct lineages (putative cryptic 76species, hereafter termed lineages $A$ and B) (Finn et al. 2014; Leys et al. 2016). These two 77lineages frequently occur in sympatry in the Swiss Alps (Leys et al. 2016). Lineage A is 
78widespread, whereas lineage $B$ is more abundant at higher elevations - raising the question 79about their ecological divergence.

80In the present study, we used field surveys of larval size distribution in two basins of the 81Swiss Alps, and population genetic analyses to gain insight into life history divergence 82between the two cryptic lineages. First, we used larval cohort structure to determine whether 83the two cryptic lineages differ in voltinism and phenology. We predicted that if the two 84lineages differ in life histories, we should see seasonally variable and distinct larval size 85distribution patterns (possibly indicating different developmental pathways and temporal 86niche partitioning). Second, we studied fine-scale population genetic structure over space and 87time within each cryptic lineage. Specifically, we tested the extent of gene flow across sites 88and between seasonal cohorts (i.e., winter vs. summer cohorts) within the lineages. For the 89latter, low genetic differentiation between winter and summer cohorts would be expected if

90 cohorts overlap in their reproductive periods or summer cohorts are produced from the 91previous winter cohorts (or vice versa). In contrast, high genetic differentiation between 92winter and summer cohorts would be expected if a given cohort is produced by a previous 93cohort of the same type. Finally, we discuss our findings on life history divergence as a 94putative facilitator of reproductive isolation and local coexistence of cryptic species.

\section{MATERIAL AND METHODS}

\section{Study species}

97Baetis alpinus (Pictet) is a common alpine mayfly of the Palearctic. The aquatic egg to larval 98stages are followed by two short-lived aerial stages: the pre-adult (subimago) and the sexually 99mature adult (imago) that only lives for a few days (Studemann et al. 1992). The larvae, 100 which tolerate a broad range of temperatures, occur in fast-flowing stony streams between 
101200 and at least $2600 \mathrm{~m}$ above sea level (a.s.l.). The larvae are scrapers and feed primarily on 102diatoms and detritus on rock surfaces (López-Rodríguez et al. 2008).

103The life cycle of B. alpinus is plastic with regard to emergence timing and voltinism (the 104number of generations per year, Humpesch 1979; Lavandier 1988; Breitenmoser-Würsten \& 105Sartori 1995; Kukula 1997; Erba et al. 2003; López-Rodríguez et al. 2008; Bottová et al. 1062013). The number of generations can range from one-half to many within a year (i.e., semi-, 107uni-, bi- to multivoltine). Two cohort types have been described when more than one 108generation per year is produced. So called "winter cohorts" are produced in autumn, 109overwinter as larvae and emerge next spring or early summer. So called "summer cohorts" 110complete egg-to-larval development in summer and emerge in late summer or autumn of the 111same year (Breitenmoser-Würsten \& Sartori 1995).

112Baetis alpinus is a typical cold-water adapted species (with optimal temperature range of 4$1138^{\circ} \mathrm{C}$ ) and has strongly temperature-dependent larval and egg development (Humpesch 1979; 114Ward \& Stanford 1982; Knispel et al. 2006). All cohorts, including winter and summer 115cohorts, overlap and timing of emergence is asynchronous (Breitenmoser-Würsten \& Sartori 1161995). Although each adult only lives for a few days, periods of flight (i.e. emergence time) 117can extend over several months (Humpesch 1979). At the adult stage, mating occurs in 118swarms, whereby females fly into male swarms to mate (Brittain 1982). Dispersal occurs 119through adult aerial flight, typically upstream along streams prior to mating, and as 120downstream drift of larvae (Thomas 1975; Lavandier 1982; Schmidt et al. 1995).

\section{Study area and general sampling design}

122The study was conducted within two glacier-fed headwater basins of the Swiss Alps, Val 123Roseg and Lötschental, located in the Danube and Rhone drainages, respectively (Figure 1). 
124Both basins have undergone severe glacial retreat over the last decades, after which 125B. alpinus colonized the newly available area (Bauder et al. 2016). These glacierized basins 126encompass a variety of streams with different dynamics in biogeochemical and physical 127characteristics (e.g., degree of glacial influence, Tockner et al. 1997). In Val Roseg, glacial 128runoff from the Tschierva and Roseg glaciers is the primary water source of the Roseg river. 129In Lötschental, the Lonza river is mainly fed by the Lang glacier. In addition, permanently 130flowing first-order tributaries contribute groundwater and snowmelt to the glacier-fed main 131channels in both valleys (see Robinson et al. 2016, for Val Roseg). Most tributaries have peak 132flows during spring/summer with increasing groundwater input towards winter (Malard et al. 1332000). Details of hydrological conditions and geological characterization of each catchment 134are given in Table S1.

135To bracket the environments that B. alpinus typically inhabit (Sartori \& Landolt 1999), we 136sampled three spring-fed tributaries and three glacier-fed main-stream sites along a 137longitudinal gradient downstream from the glacial snout within each basin (Figure 1, Table 138S2). Sampling took place monthly from April to October/November over two years (2012, 1392013). This time period typically covers the period from early larval instars to pre-adult 140emergence and egg laying (Humpesch 1979). At each site, we collected larvae to i) establish 141cohort structure based on larval size distributions (all sites; 2012-2013), and ii) identify 142cryptic lineages and their spatio-temporal distributions (subset of sites, see Figure 1 and Table 143S2; mostly 2013). One glacial main-stream site in Roseg (RM2) was sampled with higher 144resolution for genetic analyses (see below). In addition, one tributary site in Roseg (RT2) was 145investigated fortnightly for the presence of egg clutches from late June to end of October 1462013. 


\section{Environmental characterization}

148To characterize the environmental variation that developing larvae and eggs experienced, we 149measured several key parameters at each of the 12 study sites: temperature, electrical 150conductivity, periphyton (i.e., the stream biofilm harbouring microbes and detritus on stones) 151 and water chemistry. At each tributary site, water temperature was recorded hourly from July 1522012 to October 2013 using a temperature logger (HOBO UTBI-001 TidbiT Temp, Onset 153Computer Corporation, USA). At main-stream sites, the use of temperature loggers was 154prohibited due to channel instability. Here, hourly temperatures were statistically modeled 155based on spot measures and mean hourly data from the nearest hydrological station (2259156Rosegbach; 2269-Lonza) provided by the Swiss Federal Office for the Environment (FOEN) 157for 2012 and 2013 (after Ryo et al. 2016). Hourly logged data (tributaries) and modeled 158(main-stream sites) temperatures were then used to estimate daily mean temperature for each 159site. To describe the amount of heat accumulated during larval developmental periods, degree 160days (DD) were calculated for each cohort within a lineage at each site. Specifically, DD 161 correspond to the sum of daily mean stream temperatures over the presumed growth period of 162a given cohort within each lineage. The actual temperature threshold allowing B. alpinus 163larval growth is not known. Therefore, we included only values above $0^{\circ} \mathrm{C}$. To avoid bias in 164DD estimates due to different sampling dates, we considered that the larval growth period of a 165given cohort started on the first day of a given month when hatchlings were first observed (at 16601:00) and ended the last day of a given month when last-instar larvae were observed (at 16723:00).

168To quantify resource availability for developing larvae, periphyton biomass was estimated 169monthly using standardized methods (Uehlinger 1991). Periphyton was scraped with a metal 170brush from a known area from the surface of five randomly selected stones at each study site 
171on each visit (total $\mathrm{N}=360$; 5-7 dates in 2013 x 5 stones per site). The brush was rinsed with

172distilled water and the periphyton slurry filtered through pre-ashed glass fiber filters (GF/F, 173Whatmann). In the laboratory, filters were dried at $60^{\circ} \mathrm{C}$ and weighed, then combusted at $174550^{\circ} \mathrm{C}$ and reweighed, with the difference in mass after drying and combusting representing 175the ash free dry mass.

176On each sampling date at each site, water electrical conductivity $\left(\mu \mathrm{Scm}^{-1}\right.$ at $\left.20^{\circ} \mathrm{C}\right)$ was 177measured with a conductivity meter (LF323; WTW, Weilheim, Germany). A water sample 178(0.5 L) was also collected for later chemical analysis in the laboratory ( $\mathrm{N}=9$ dates per site). 179Water samples were stored in polyethylene bottles placed in the dark in a cool box and 180processed within $24 \mathrm{~h}$ of collection. Conductivity indicates stream ion concentration and 181potential source of water (e.g., glacial melt, groundwater). Other water quality measures taken 182 from each water sample included $\mathrm{pH}$, particulate organic carbon (POC), dissolved organic 183carbon (DOC), dissolved organic nitrogen (DN), particulate organic nitrogen (PN), 184phosphate-P $\left(\mathrm{PO}_{4}^{-} \mathrm{P}\right)$, particulate phosphorus (PP), and silicate $\left(\mathrm{H}_{4} \mathrm{SiO}_{4}\right)$. These were 185determined in the laboratory according to standard protocols detailed in Tockner et al. (1997).

\section{Life history variation of B. alpinus}

187To analyze seasonal variation in B. alpinus cryptic lineage distributions and abundance, and to 188characterize life cycles, larval samples were collected monthly over two years (Roseg: April 1892012 - October 2013; Lötschental: June 2012 - October 2013). Sampling was done using a 190standard kick-net (250- $\mu m$ mesh) across all meso-habitats at a given site. To ensure adequate 191sample sizes, sampling was conducted until ca. 150 larvae were collected (if possible) at each 192sampling date and site. In Lötschental main-stream sites, relatively few larvae (7-32 193individuals per site) were found in August 2012 due to an earlier flood. Larvae were 194preserved in $75 \%$ ethanol in the field. A subset of larvae were verified in the laboratory 
195following the taxonomic key of Studemann et al. (1992), and subsequently preserved in 96\% 196ethanol for later genetic analysis. Given that it was not possible to individually examine each 197larvae for logistic reasons, and that early-instars are morphologically undistinguishable, the 198larval size data may include some individuals of the closely related species B. melanonyx (see 199below). This species belongs to the B.alpinus species group and is superficially 200morphologically similar to B. alpinus (Bauernfeind \& Soldán 2012). In our previous work, 201B. melanonyx was found at low to moderate abundance (2-36\%) in Lötschental (Leys et al. 2022016). Although we cannot completely account for bias caused by B. melanonyx in the larval 203size data, we expect this bias to be minimal given the rarity of this species at our study sites 204(i.e., only 11 out 800 genotyped larvae belonged to B. melanonyx; see below).

205Life cycle analyses were based on temporally repeated measurements of larval size (i.e., total 206body length) distributions within each site. Larvae were placed laterally on a microscope 207glass-slide and digital images taken of each specimen at 20-160x magnification (depending on 208the size of the specimen) using a digital camera mounted on a dissecting microscope (Leica 209M205C). Total larval body length from the anterior edge of the labrum to the posterior edge 210of the last abdominal segment was measured from the digital images and fitted as a cubic 211spline curve using ImageJ software (Schneider et al. 2012). A total of 12641 larvae of the 212B. alpinus species group were measured for size.

213To account for the effects of sex on size, as well as to gain initial insight into sex ratios at our 214study sites, the sex of B. alpinus larvae was determined for larvae collected in $2013(\mathrm{~N}=2730$ 215 specimens). An individual was determined as male if it showed a dimorphic structure of the 216compound eyes, as females lack this trait (Verrier 1956). This sexual character appeared in 217our dataset for larvae larger than $3.5 \mathrm{~mm}$ in size (M. Leys, personal observation). 


\section{Genetic data collection}

219DNA was extracted using the HotSHOT method (Montero-Pau et al. 2008). To optimize 220representativeness and laboratory effort, two tributary and two main-stream sites per basin 221 were included in the genetic analyses. We used this dataset to identify cryptic lineages and to 222quantify within-lineage population genetic structure at 8 of the 12 study sites (see Figure 1). 223To identify the lineage of hatchlings and emergent last-instars, the six smallest and six largest 224individuals within each site and sampling date were genotyped at 10 unlinked and 225polymorphic nuclear microsatellite markers $(\mathrm{N}=608$ specimens, Leys et al. 2016). This 226selection strategy was determined based on an exhaustive genotyping of specimens across all 227size classes at one Roseg main-steam site (RM2) across four sampling dates $(\mathrm{N}=192$ 228specimens). A total of 800 specimens were genotyped. Polymerase chain reaction (PCR) 229amplification, allele-sizing, electrophoresis and genotyping on an ABI 3730xl DNA Analyzer 230(Applied Biosystems) were performed as in Leys et al. (2016).

\section{Statistical analyses}

\section{Environmental variation}

233To assess environmental differences among sites and seasonal variation within sites, we first 234ran a principal component analysis (PCA) on eight weakly correlated variables $(r<0.6$; $\mathrm{N}=$ 23577 observations): mean monthly stream temperature, silicate, particulate phosphorus, 236particulate organic nitrogen, particulate organic carbon, periphyton biomass and electrical 237conductivity. We then performed a permutational multivariate analysis of variance 238(PERMANOVA, Anderson 2001) using the environmental dissimilarity matrix based on all 239variables to test for the effects of space and time (basin, stream-type, site and sampling date as 240fixed effects). Significance was assessed using 10000 permutations in the vegan R package 241(R Core Team 2016). 
242Cohort structure at the morphospecies level

243Cohorts were estimated based on the monthly B. alpinus larval sizes, first within the 244morphospecies and then within each of the two genetic lineages separately. This approach 245allows us to assess to what extent the variability in voltinism described in the literature (at the 246morphospecies level) is in fact caused by differences between the two lineages (see 247discussion). We also took advantage of the large sample sizes of the morphospecies to better 248allow inference of life-cycle differences between lineages. A cohort was defined to have 249started when small nymphs (ca. 0.5 to 1-mm size larvae) appeared and to have ended when 250last-instar individuals appeared (visually distinguishable by wing-pad development and 251coloration) within a defined time interval.

252Statistically, each monthly larval size distribution was considered as a mixture of probability 253density distributions (i.e., the mixture distribution is formed by the combination of individual 254distributions, the mixture components). We fitted continuous finite mixture models assuming 255that larval sizes followed a Gaussian distribution using the package mclust for R (Fraley \& 256Raftery 2007). For each date and site, models with different numbers of mixture components 257were compared using the Bayesian information criterion. Each genotyped individual (see 258below) was then assigned to a particular mixture component using the predict function.

259Once the most likely number of mixture components was determined for each month and site, 260temporally consecutive mixture components (i.e., assuming that mean larval size increased 261 from hatching to emergence) were assigned to a given cohort (Figure 2, S1). In some cases 262(RM2: Jul-2012, Jul-2013; RM3: May-2013; RT2: Jul-2012, Jul-AUG 2013; LM3: May-Jul 2632013; LM5: Jun-2013), the most likely number of mixture components was estimated as one 264despite the presence of very small (i.e., hatchlings) and large (last instars) individuals - which 265are unlikely to belong to the same cohort. In these cases, we deduced the most likely number 
266of mixture components from the precedent and subsequent month, taking into account 267possible emergence or new recruitment.

\section{Cryptic lineage delineation}

269We applied a Discriminant Analysis of Principal Components (DAPC, Jombart et al. 2010) to 270assign the subset of individuals (see above) to one of the two cryptic lineages. As a 271preliminary step, microsatellite data from the Roseg and Lötschental basins used in Leys et al. 272(2016) were included in the analysis to allow assignment of individuals to the two B. alpinus 273lineages (lineages $A$ and $B$ ) and to $B$. melanonyx. Eleven individuals (1.4\%) were identified as 274B. melanonyx and discarded in subsequent analyses. The DAPC analysis also was performed 275 for the dataset only including $B$. alpinus individuals $(\mathrm{N}=789)$. For this analysis a total of 50 276principal components (PCs) were retained, accounting for $83.3 \%$ of the total genetic 277variability. This resulted in identical lineage assignments. All analyses were conducted using 278adegenet 2.0.1 for R (Jombart 2008).

\section{Within-lineage cohorts and spatio-temporal genetic differentiation}

280To test whether the two lineages are randomly distributed within the morphospecies cohorts, 281we calculated the proportion of each lineage within a cohort in a 2 x 2 contingency table for 282each site and performed a Chi-square test of independence (Supplementary Table S3). To gain 283insight into both the approximate mating period (based on the time period when emergence

284occurs), as well as putative temporal isolation in mating time between lineages, adult 285emergence (all sites) and egg laying (Roseg tributary site RT2) periods were identified. 286Finally, a factorial ANOVA was used to test tentatively for differences in size between sexes 287and lineages at the onset of emergence. For this, all available last-instar larvae were used $(\mathrm{N}=$ 28822, Figure S2). 
289The following analyses were performed separately for each cryptic lineage. Genetic 290differentiation among relevant groups (e.g., sites or cohorts) was quantified by the $F_{\text {Sт }}$ index 291according to Weir \& Cockerham (1984). First, we calculated pairwise $F_{\mathrm{ST}}$ 's among different 292sites (cohorts being pooled within sites) and, second, between cohorts within a specific site 293using FSTAT (Goudet 1995). To gain insight into the extent of genetic differentiation among 294sites and among cohorts, we estimated variance components attributable to i) individuals 295within cohorts (including only sites and dates with a minimum of eight individuals), ii) among 296cohorts within a site, iii) among sites within stream-type (glacier-fed vs. spring-fed), and iv) 297between stream-type within each basin (see Figure 3), as well as respective hierarchical F298statistics using the R package hierfstat (Goudet 2005). Statistical significance was assessed 299using 10000 permutations.

300To visualize the relatedness of the winter and summer cohorts and genetic variation among 301individuals within cohorts, DAPC was performed using cohorts (at a particular site; here only 302sites with a minimum of eight individuals were included) within a given basin as a-priori 303groups (Jombart et al. 2010). For lineage A, the analysis was based on 50 PCs in Roseg and 30440 PCs in Lötschental, both accounting for $85.1 \%$ of the total genetic variation. For lineage $B$ 305in Roseg (sample size was insufficient in Lötschental), DAPC was based on 25 PCs 306accounting for $87.8 \%$ of the total genetic variation.

307 Next, we tested for an association between cohort structure and genetic distance between 308individuals (within each site) using a partial Mantel test based on three distance matrices: i) 309individual pairwise genetic distances (Cavalli-Sforza \& Edwards 1967), ii) pairwise cohort 310distance (i.e., distance in cohort number for temporally ordered cohorts), and iii) a distance 311matrix indicating whether two individuals belong to one of the three cohort categories: 312summer-summer, winter-winter or winter-summer. The significance of $r$ values was tested 
313with a partial Mantel test (10,000 permutations) performed in the package $n c f$ for $\mathrm{R}$ 314(Bjørnstad 2016).

315Finally, we examined spatial and temporal patterns of genetic variability across cohort types 316(i.e., between summer-summer, winter-winter and summer-winter cohorts) using 317autocorrelation analyses at one main-stream site in Roseg (RM2 where sample size was 318sufficiently large). We used the kinship coefficient $F_{\mathrm{ij}}$ (Loiselle et al. 1995) as an 319autocorrelation index and seven 'distance classes' of cohorts (i.e., the distances reflect the 320number of cohorts between temporally ordered cohorts). We calculated confidence intervals 321by permuting cohort number distance (under the null hypothesis of no temporal genetic 322structure) with 10000 permutations of individuals using SPAGeDI version 1.5 (Hardy \& 323Vekemans 2002).

\section{Variation related to sex}

325We compared monthly larval size distributions of males and females. Sex-ratios and 95\% 326binomial proportion confidence intervals were calculated i) at the morphospecies level for 327each sampling date at a particular site (all sites), and ii) at the lineage level within each cohort 328at the Roseg main-stream site RM2. We tested whether sex-ratios deviated from 1:1 within 329these different levels using binomial tests using the function binom.test from the R library 330stats (R Core Team 2016).

\section{RESULTS}

\section{Environmental variation}

3330rdination of environmental parameters by PCA revealed strong spatial and seasonal 334variation (Figure S3). PERMANOVA on the environmental dissimilarity matrix indicated 
335significant effects of stream-type $\left(R^{2}=0.17, \mathrm{~F}_{1,59}=24.20\right)$, site $\left(R^{2}=0.21, \mathrm{~F}_{9,59}=3.34\right)$, basin 336 $\left(R^{2}=0.04, \mathrm{~F}_{1,59}=5.40\right)$ and season (month: $R^{2}=0.17, \mathrm{~F}_{6,59}=4.04$; all $\left.P<0.001\right)$.

337The main-stream sites (ranging from 0.0 to $8.8^{\circ} \mathrm{C}$, mean \pm sd: $2.3 \pm 2.0^{\circ} \mathrm{C}$ ) were typically 338 colder than the tributaries (ranging from -0.8 to $15.4^{\circ} \mathrm{C}$, mean $\pm \mathrm{sd}$ : $4.4 \pm 3.6^{\circ} \mathrm{C}$; Figure S4), 339reflecting a glacial influence and larger volume of water. An exception were Roseg main340stream sites $R M 2$ and $R M 3$, which were relatively warmer because they are located below a 341lake outlet (Figures 1, S4, Finn et al. 2010). Moreover, daily mean temperatures increased

342with distance from the glacier in the main-stream sites (Figure S4). Tributaries differed in 343mean and variation of temperature, likely due to groundwater inputs and coarse-scale spatial 344attributes (e.g., north vs. south-facing slope).

345Mean periphyton biomass increased in autumn (i.e., when glacier run-off decreases in glacial 346streams (Uehlinger et al. 2010), and differed also among sites (Figure S5a). The highest 347periphyton biomass was measured at RT3 in Roseg and LT4 in Lötschental, indicating higher 348resource availability for developing larvae in these tributaries (Figure S5b).

\section{Life history variation}

350Cohort structure at the morphospecies level

351Larvae of B. alpinus were abundant at nearly all sites and sampling dates (the glacial RM1 site 352in Roseg, however, had abundant early-instar larvae only in early spring; Figures S1, S6). 353Last-instar larvae were found from June to October, suggesting that B. alpinus reproduces 354from early summer to autumn at our study sites (Figure S6). This was further supported by 355egg clutches being found from mid-June to late October (data on Roseg tributary RT2). 
356Cohort delineation analysis at the morphospecies level indicated a multivoltine life cycle, with 357three to four overlapping cohorts (sensu Clifford 1982, Figure 2). Specifically, the 358morphospecies appeared to consist of both winter (i.e., overwintering as hatched larvae with 359winter/spring larval development and emergence in early summer) and summer (i.e., 360embryonic and larval development during spring and summer, and emergence in summer and 361autumn) cohorts (Figures 2, S1 and S6).

362Based on larval size distributions, the earliest winter cohort within a given site (henceforth 363named a) hatched in September, with subsequent overwintering as early larval instars, and 364emergence taking place in late-spring to early summer (e.g., cohort $a 2$ in Roseg glacial 365stream-site RM2-2012 and 2013; Figure 2). A second winter cohort (henceforth named $b$ ) was 366indicated by the presence of early instars in October-November, concomitant with the 367presence of larger nymphs and last-instar larvae in late July (e.g., cohort b2 in Roseg glacial 368stream-site RM2-2012 and 2013). These two apparent winter cohorts ( $a$ and $b$ ) were followed 369by one or two (depending on site and year) fast developing summer cohorts ( $c$ and $d$; Figure 3702). Development time of the winter cohorts ranged from 10 to 11 months and that of summer 371 cohorts from two to three months (e.g., $c 1$ in Roseg glacial stream-site RM2-2012, $d 1$ in $R M 2-$ 3722012). Based on the appearance of last-instar larvae, emergence phenology varied between 373years and among sites (Figure S6). Monthly larval size distribution for each sex, as well as 374sex-ratios, suggested that the inferred cohort structure is not strongly confounded by size 375differences of males and females (Figures S7, S8).

376Novel insight from genotyping: cryptic lineage life history divergence

377A total of 789 B. alpinus individuals were genotyped. Of these, the DAPC unambiguously 378assigned 642 individuals to lineage $A$ and 147 individuals to lineage $B$ (Figure 4a). The 379lineages were strongly genetically distinct $\left(F_{\mathrm{ST}}=0.203\right)$. Both lineages occurred at most sites 
380(with the exception of main stream-site $R M 3$ in Roseg where no lineage $B$ individuals were 381found; Figure 4b). Lineage $A$ was more abundant than lineage $B$ at all sites, with an increasing 382prevalence of lineage $B$ at higher elevations (from 0 at lowest site to $26.8 \%$ at highest site; 383averaged across sampling dates, Table S3 and Figure 4b).

384The relative frequencies of lineage $A$ and $B$ individuals differed significantly among the 385morphospecies-based cohorts (Pearson Chi-square test of independence: all $P<0.0001$ except 386tributary RT4 in Roseg and main- stream site LM5 in Lötschental where very few lineage $B$ 387individuals were observed; see Table S3), suggesting that the lineages differ in life histories. 388Subsequent lineage-specific cohort analyses support this view. First, lineage $A$ appears to 389have a bivoltine (tributaries LT2, LT4 in Lötschental, RT2 in Roseg) to multivoltine life cycle 390(e.g., main stream-site RM3 in Roseg), including one to several summer and winter cohorts 391(Figure 4). For the winter cohorts, appearance of small nymphs started typically in September 392- October and last-instar larvae were observed in June - July. The larval period of lineage A 393winter cohort spanned 10 to 11 months. For the summer cohort of lineage $A$, hatchlings were 394observed in August and last-instar larvae were observed in September - October, indicating a 395larval period of two-three months. In contrast, lineage $B$ appears to be consistently univoltine, 396with a single summer cohort: larval development began in late May, June or early July, 397 followed by a growth period of ca. three to five months and emergence in July to September 398(Figure 4b). Based on the appearance of last-instars, emergence occurred from July to October 399in lineage $A$ and in August in lineage $B$ (Figure 4). This result indicates some temporal 400differentiation, but also temporal overlap in mating times between the lineages.

401Based on the association between the larval development period of a given cohort (within 402each lineage) and thermal conditions during a given period, cohorts of each lineage 403experienced different thermal conditions (Figure 4, Table S4). However, the patterns were 
404somewhat inconsistent between the basins. In Lötschental, DDs of larval developmental 405periods appeared, on average, higher for lineage $A$ winter cohorts and for lineage $B$ than for 406lineage $A$ summer cohorts. In Roseg, DDs of lineage $A$ winter cohorts were equivalent or 407lower than for summer cohorts (Table S4).

\section{Within-lineage population genetic differentiation}

409The hierarchical analysis of population genetic differentiation within lineage $A$ showed that a 410significant amount of genetic variance was explained by cohort (within site) in both basins. 411Genetic variance explained by stream-type was of similar magnitude, but not significant (both $412 P=0.16$, Table 1 and Figure 3; possibly due to low statistical power). Pairwise $F_{\mathrm{ST}}$ indicated 413subtle genetic differentiation between sites and between cohorts (Figure S9). Furthermore, 414DAPC analyses, using cohorts within each lineage as prior groups, indicated that winter and 415summer cohorts were moderately genetically differentiated (Figure 5). These results were 416consistent with both Partial mantel tests and temporal autocorrelation analyses: pairs of 417individuals where one belonged to a summer and the other to a winter cohort were genetically 418more dissimilar than pairs where both individuals belonged to summer cohorts or winter 419cohorts, respectively, even when accounting for possible temporal effects (partial Mantel 420tests, all $P<0.01$ except for Roseg main-stream site $R M 3$ and tributary RT4; Table 2 and 421Figure S10).

\section{DISCUSSION}

423Life history trait divergence in morphologically similar but genetically distinct cryptic 424lineages can provide insight into adaptation, mechanisms of species coexistence, as well as 425population dynamics. Our study on B. alpinus indicates clear divergence of two co-occurring 426cryptic lineages in life cycles and spatio-temporal dynamics. Specifically, we found that 427lineage $A$ is relatively more abundant locally and has a bi- to multivoltine life cycle, whereas 
428lineage $B$ has a consistently univoltine life cycle. In a previous study, we further showed that 429lineage $A$ is more widely distributed across the Swiss alps and harbors more neutral genetic 430diversity than lineage $B$ (Leys et al. 2016). Taken together, these findings support the view 431that lineage $A$ represents a generalist lineage, whereas lineage $B$ likely is more specialized to 432high mountain conditions. We next discuss the implications of such life history divergence for 433the evolutionary ecology of cryptic lineages in general and for B. alpinus specifically.

\section{Contrasting inference from morphospecies vs. cryptic lineage life-cycles}

435The accuracy of biodiversity assessments and predictions of responses to climate change 436strongly depends on a robust analysis of species boundaries and differences in ecology (Pauls 437et al. 2013). This point is clearly illustrated in our comparisons of life cycles based on 438morphospecies vs. cryptic lineage identities. At the morphospecies level, analysis of larval 439cohort structure in B. alpinus indicated the presence of two or more generations at most study 440sites. However, the two cryptic lineages clearly showed different life history strategies. First, 441lineage $A$ had a bivoltine to multivoltine life cycle that consisted of winter cohorts 442(overwintering as larvae) and summer cohorts (completing larval development from hatching 443to emergence in summer). In contrast, lineage $B$ was consistently univoltine with one fast 444growing summer cohort at all sites (larval development completed in 3-5 months; Figure 4).

445The lineage $A$ winter and summer cohorts differed in the length of the larval period (10-11 446months in winter cohorts vs. 2-3 months in summer cohorts) and thereby winter and summer 447cohorts experience different larval growth conditions. The winter cohort hatched in 448September-October and emerged first in June-July of the following year. Hence, the larvae 449presumably faced very low temperatures slowing down (or possibly even arresting) 450development until temperatures increase in spring. In contrast, larvae of the summer cohorts 451started developing in July-August and emerged in September-October. These larvae therefore 
452likely faced favorable growth conditions resulting in faster growth and shorter developmental 453periods.

454Interestingly, lineage $B$ showed yet another life history pattern. The univoltine life cycle of 455this lineage consisted of summer cohorts, which - in contrast to lineage $A$ - appeared to 456overwinter as embryos. Embryonic diapause is indicated by emergence (and also egg laying at 457Roseg tributary, RT2) taking place in summer/autumn, but hatchlings not being detected 458before the following spring (Figure 4). This observation is intriguing. Although the life cycle 459of B. alpinus has been extensively studied over decades (e.g., Humpesch 1979; Lavandier 4601988; Breitenmoser-Würsten \& Sartori 1995; Kukula 1997; Erba et al. 2003; Knispel et al. 4612006; López-Rodríguez et al. 2008; Bottová et al. 2013), our study provides the first 462 indication of embryonic diapause in this species.

463To what extent these differences in life-cycles between the two lineages in the wild reflect 464phenotypic plasticity and/or genetically determined differences in developmental pathways is 465thus far unclear. Given that ectotherms (including B. alpinus) strongly respond to variation in 466thermal conditions during development, environmentally induced phenotypic plasticity is 467certainly likely (Angilletta 2009). However, genetic divergence in developmental pathways468in response to divergent natural selection via temperature and seasonal time constraints - is 469also possible. Such divergence has been shown in damselflies (Sniegula et al. 2016), 470Drosophila (Barker et al. 2011), frogs (Muir et al. 2014) and other taxa (reviewed in Keller et 471al. 2013). Clearly, further studies on determinants of life-cycle variation in this system are 472needed. Here experiments under controlled laboratory conditions, concomitant to genomic 473tools to establish the genetic basis of trait divergence, would be particularly useful. 
4750ur study comes with some caveats that need to be addressed in future studies. First, the 476presence of young and intermediate-instar larvae continuously throughout the year did not 477always allow us to unambiguously determine the beginning and end of a given generation 478(Figures 2, S1, S6). However, two approaches helped to increase accuracy of cohort 479assignments. Monthly larval size distributions combined with statistical inferences (maximum 480likelihood estimation of Gaussian mixture models), allowed us to determine cohorts more 481objectively than the often-used visual inspections of size frequency histograms (e.g., Erba et 482al. 2003; López-Rodríguez et al. 2008). Likewise, monitoring the presence/absence of eggs at 483one tributary (RT2) allowed us to link the temporal presence of eggs to the appearance of 484hatchlings.

485A second potential source of error for cohort inferences comes from using pooled data from 486males and females (it was not possible to reliably sex all larval stages). This could introduce 487bias to life-cycle estimates if males and females differ in larval growth patterns (i.e., part of 488the variation may be due to sex ratio differences over time or space). Such sex-specific 489differences have been shown in B. rhodani, a mayfly genetically related to B. alpinus: 490B. rhodani females are larger than males at emergence because they have more instars and 491emerge later than males (Elliott 2013). Our data tentatively indicate that sex ratios may differ 492across sites (possibly between lineages) and that the sexes differ in size at emergence (males 493being smaller than females, Figure S2). However, life history divergence of lineages was 494consistently detected at multiple sites, suggesting that effects of sexual dimorphism on cohort 495structure were minor. Given the small sample sizes further studies on sex-specific variation in 496life-cycles are warranted however. 


\section{Alternative life history strategies and lineage coexistence}

498Seasonal environments can impose strong selection on reproduction and organismal 499development due to environmental fluctuations and time constraints (Roff 2002; Kivelä et al. 5002013). The adaptive value of the life-cycle variation seen here need yet to be directly tested, 501but several adaptive explanations are likely. First, direct development (as apparent in lineage 502A) can allow more generations per year than a life-cycle with embryonic diapause (as 503presumably is the case in lineage $B$ ). On the other hand, embryonic diapause likely represents 504an adaptive overwintering strategy that prevents exposure of temperature-sensitive larval 505stages to unfavorable conditions (e.g., Tauber \& Tauber 1981). Furthermore, the presence of 506multiple overlapping cohorts and variation in emergence time (as in lineage $A$ ) may be 507adaptive in unpredictable environments. In alpine environments, unpredictable climate 508variation (Scherrer et al. 2004) may favor a bet-hedging strategy, whereby the distribution of 509reproduction over the entire season may reduce the probability that entire generations are 510wiped out by catastrophic events (Kiss \& Samu 2005; Wilbur \& Rudolf 2006). Finally, 511 competition for resources may favor a mixture of larval phenotypes and induce density512dependent processes that favor different hatching and emergence periods (Iwasa et al. 1994; 513Elliott 2013).

514The observed spatio-temporal differences in larval cohort structure and egg laying periods 515indicate some seasonal partitioning between the two cryptic lineages (Figure 4). Such 516temporal divergence may reflect past divergent selection in geographic isolation and 517subsequent secondary contact, or evolutionary divergence in situ. Irrespective of the 518evolutionary history, such seasonal segregation may favor the coexistence of these closely 519related and morphologically similar lineages by minimizing the temporal overlap in resource 
520use and competition (Armstrong \& McGehee 1976; Armstrong \& McGehee 1980; Chesson

5211985; Chesson 2000). These hypotheses need to be explicitly tested, however.

\section{Within-lineage population genetic differentiation}

523We found subtle but significant neutral genetic divergence across our study sites, indicating 524some spatial limits to gene flow, but no clear evidence for habitat isolation within lineages. 525Given the highly dynamic nature of alpine basins (possibly favouring metapopulation 526dynamics), such moderate spatial isolation within basin is not surprising. More interestingly, 527we found moderate and significant genetic structure between seasonal cohorts within lineage 528A. Specifically, winter cohorts were genetically more related to other winter cohorts than to 529the subsequent summer cohorts (which would be nearest in terms of absolute time). This 530suggests that a given winter cohort produces the next winter cohort and that individuals from 531different summer/winter cohorts do not represent a panmictic population. It is also possible, 532however, that winter cohorts partly produce summer cohorts, but that the cohort types are 533genetically distinct due to, for instance, founder effects (Lenfant \& Planes 2002). 534Interestingly, Landa (1969) found differences in larval morphology (i.e., in the middle caudal 535filament) between winter and summer cohorts of bivoltine populations in B.alpinus. 536Assuming this variation does not reflect unknown cryptic species (an option we cannot 537exclude, although we found no evidence for such differences between lineage $A$ and $B$, Leys 538et al. 2016), this finding would further support ecological and genetic differentiation between 539cohort types. Overall, our results suggest complex spatial and temporal patterns of gene flow, 540likely resulting from within basin interactions between life history variation, adult dispersal 541and local bottlenecks (e.g., due to hydroperiod mediated variation in oviposition site 542availability, Peckarsky et al. 2000; Caudill 2003). 


\section{General implications and outlook}

544Here we provide novel evidence of life-cycle divergence between two cryptic lineages of a 545widely distributed alpine mayfly. When undetected, such ecological divergence between 546cryptic lineages can confound estimates of the spatial distribution and ecological niche of a 547species (Leys et al. 2016). Specifically, unreliable estimates of environmental requirements, 548life histories and reproductive characteristics of organisms can have significant repercussions 549for many ecological and evolutionary research fields, as well as estimates of biodiversity (e.g., 550Feckler et al. 2014; Pante et al. 2015). Our results clearly support the need for accurate 551delimitation of evolutionary units (Crandall et al. 2000; Brodersen \& Seehausen 2014). In 552particular, instead of a highly variable and phenotypically plastic species with a wide 553ecological niche (as previously has been repeatedly suggested), B. alpinus is a mix of 554apparent generalists (here lineage $A$ ) and specialists (here lineage $B$ ) that are reproductively 555isolated.

556Yet several key questions are left open for our study system. First, what is the adaptive value 557of these generalist and specialist strategies as well as their responses to climate change? 558Ultimately these are determined both by fitness benefits and trade-offs, and extent of 559phenotypic plasticity versus heritable genetic variation (Merilä \& Hendry 2014), necessitating 560explicit experimental tests in the future. Second, what are the mechanisms of reproductive 561 isolation between these divergent lineages? The lineages showed partial temporal segregation 562in reproductive periods, but additional quantitative field data on key reproductive parameters 563(e.g., emergence times, swarming sites, sex ratios of emerging adults) would be particularly 564valuable for estimating putative overlap (or lack thereof) of mating times and sites between 565the lineages. Finally, what are the processes that produced this life history divergence and to 566what extent does this divergence influences co-existence of these morphologically similar 
567lineages? On one hand, this divergence may have occurred in response to divergent natural 568selection unrelated to resource use, but currently facilitate spatial coexistence due to reduced 569inter-specific competition. Alternatively, resource competition may have directly facilitated 570ecological trait divergence and reproductive isolation (i.e., ecological character displacement, 571Pfennig \& Pfennig 2009; Stuart \& Losos 2013). Further research is needed to infer whether 572the observed divergence was a result of past independent adaptation to different niches and/or 573a result of sympatric evolution in situ. Given likely different historical distribution ranges of 574these lineages and secondary contact upon range expansion, past isolation is certainly possible 575(Leys et al. 2016). Our study highlights the value of temporally replicated phenotypic and 576 genetic surveys of cryptic lineages in the wild: integrating such data can aid in assessing life 577history variation of cryptic species and is critical for understanding their evolutionary past and 578their future responses to environmental change.

\section{ACKNOWLEDGEMENTS}

580Genetic data analyzed in this paper were generated at the Genetic Diversity Centre (GDC), 581ETH Zurich. We warmly thank S. Blaser for valuable field and laboratory post-processing 582assistance, Lisa Breithut and P. Ganesanandamoorthy for laboratory genetic analysis 583assistance, M. Seymour, M. Sertić Perić, M. Dziuba, M. Reyes, C. Thompson for field 584support, the AUA lab team for analysis of water samples, T. Diethelm and K. Ruprecht for 585larval digital image processing, R. Masahiro for providing the glacier-fed site temperature 586estimates, C. Roux for helpful R coding hints, and J.-F. Arnaud for helpful discussions and 587comments on this manuscript. We thank the anonymous reviewers for helpful comments that 588improved the paper. The temperature data from hydrologic stations were kindly provided by 589the Swiss Federal Office for the Environment. This study was funded by the Swiss National 590Foundation (No. 31003A_135523). 


\section{REFERENCES}

592Adams M, Raadik TA, Burridge CP, Georges A (2014) Global biodiversity assessment and 593 hyper-cryptic species complexes: more than one species of elephant in the room? 594 Systematic Biology, 63, 518-533.

595Anderson MJ (2001) A new method for non-parametric multivariate analysis of variance. 596 Austral Ecology, 26, 32-46.

597Angilletta MJ (2009) Thermal Adaptation: A Theoretical and Empirical Synthesis Oxford $598 \quad$ University Press, UK, Oxford.

599Armstrong RA, McGehee R (1976) Coexistence of species competing for shared resources. 600 Theoretical Population Biology, 9, 317-328.

601Armstrong RA, McGehee R (1980) Competitive exclusion. American Naturalist, 115, 151$602 \quad 170$.

603Barker JSF, Frydenberg J, Sarup P, Loeschcke V (2011) Altitudinal and seasonal variation in 604 microsatellite allele frequencies of Drosophila buzzatii. Journal of Evolutionary 605 Biology, 24, 430-439.

606Bauder A, Fischer M, Funk M, Huss M, Kappenberger G (2016) The Swiss glaciers 607 2011/2012 and 2012/2013. In: Glaciological Report n $133 / 134$ (ed. Bauder A), p. 118 608 pp. Cryospheric Commission (EKK) of the Swiss Academy of Sciences (SCNAT) and 609 laboratory of Hydraulics, Hydrology and Glaciology (VAW), ETH Zürich.

610Bauernfeind E, Soldán T (2012) The mayflies of Europe (Ephemeroptera) Appollo Books, 611 Ollerup, Denmark.

612Bickford D, Lohman DJ, Sodhi NS, et al. (2007) Cryptic species as a window on diversity 613 and conservation. Trends in Ecology \& Evolution, 22, 148-155.

614Bjørnstad ON (2016) ncf: spatial nonparametric covariance functions. R package version 1.1615 7.

616Bolnick DI, Svanback R, Fordyce JA, et al. (2003) The ecology of individuals: incidence and 617 implications of individual specialization. American Naturalist, 161, 1-28.

618Bottová K, Derka T, Svitok M (2013) Population dynamics of mayflies in a constant 619 temperature spring stream in West Carpathians. Limnologica, 43, 469-474.

620Breitenmoser-Würsten C, Sartori M (1995) Distribution, diversity, life cycle and growth of a 621 mayfly community in a prealpine stream system (Insecta, Ephemeroptera). 622 Hydrobiologia, 308, 85-101.

623Brittain JE (1982) Biology of mayflies. Annual Review of Entomology, 27, 119-147.

624Brodersen J, Seehausen O (2014) Why evolutionary biologists should get seriously involved 625 in ecological monitoring and applied biodiversity assessment programs. Evolutionary 626 Applications, 7, 968-983. 
627Carothers JH, Jaksic FM (1984) Time as a niche difference : the role of interference 628 competition. Oikos, 42, 403-406.

629Caudill CC (2003) Empirical evidence for nonselective recruitment and a source-sink 630 dynamic in a mayfly metapopulation. Ecology, 84, 2119-2132.

631Cavalli-Sforza LL, Edwards AWF (1967) Phylogenetic analysis models and estimation 632 procedures. American Journal of Human Genetics, 19, 233-\&.

633Chesson P (2000) Mechanisms of maintenance of species diversity. Annual Review of $634 \quad$ Ecology and Systematics, 31, 343-366.

635Chesson PL (1985) Coexistence of competitors in spatially and temporally varying 636 environments: a look at the combined effects of different sorts of variability. 637 Theoretical Population Biology, 28, 263-287.

638Clifford HF (1982) Life cycles of mayflies (Ephemeroptera), with special reference to 639 voltinism. Quaestiones Entomologicae, 18, 15-90.

640Crandall KA, Bininda-Emonds ORP, Mace GM, Wayne RK (2000) Considering evolutionary 641 processes in conservation biology. Trends in Ecology \& Evolution, 15, 290-295.

642Danks HV (1994) Diversity and integration of life-cycle controls in insects. In: Insect life643 cycle polymorphisms (ed. Danks HV), pp. 5 - 40. Kluwer Academic Publishers Group, 644 Dordrecht, Netherlands.

645Elliott JM (2013) Contrasting dynamics from egg to adult in the life cycle of summer and 646 overwintering generations of Baetis rhodani in a small stream. Freshwater Biology, $647 \quad 58,866-879$.

648Erba S, Melissano L, Buffagni A (2003) Life cycles of Baetidae (Insecta: Ephemeroptera) in a 649 North Italian Prealpine stream. In: Research update on Ephemeroptera and 650 Plecoptera (ed. Gaino E), pp. 177-186. University of Perugia Press, Perugia, Italy.

651Feckler A, Zubrod JP, Thielsch A, et al. (2014) Cryptic species diversity: an overlooked 652 factor in environmental management? Journal of Applied Ecology, 51, 958-967.

653Finn DS, Räsänen K, Robinson CT (2010) Physical and biological changes to a lengthening 654 stream gradient following a decade of rapid glacial recession. Global Change Biology, 655 16, 3314-3326.

656Finn DS, Zamora-Muñoz C, Múrria C, Sáinz-Bariáin M, Alba-Tercedor J (2014) Evidence 657 from recently deglaciated mountain ranges that Baetis alpinus (Ephemeroptera) could 658 lose significant genetic diversity as alpine glaciers disappear. Freshwater Science, 33, $659 \quad 207-216$.

660Fraley C, Raftery AE (2007) Model-based methods of classification: Using the mclust 661 software in chemometrics. Journal of Statistical Software, 18, 1-13.

662Gill BA, Kondratieff BC, Casner KL, et al. (2016) Cryptic species diversity reveals 663 biogeographic support for the 'mountain passes are higher in the tropics' hypothesis. $664 \quad$ Proceedings of the Royal Society B-Biological Sciences, 283, 20160553. 
665Goudet J (1995) FSTAT (Version 1.2): A computer program to calculate F-statistics. Journal 666 of Heredity, 86, 485-486.

667Goudet J (2005) HIERFSTAT, a package for R to compute and test hierarchical F-statistics. $668 \quad$ Molecular Ecology Notes, 5, 184-186.

669Hardy OJ, Vekemans X (2002) SPAGeDi: a versatile computer program to analyse spatial 670 genetic structure at the individual or population levels. Molecular Ecology Notes, 2, 671 618-620.

672Humpesch UH (1979) Life cycles and growth rates of Baetis spp. (Ephemeroptera: Baetidae) 673 in the laboratory and in two stony streams in Austria. Freshwater Biology, 9, 467-479.

674Iwasa Y, Ezoe H, Yamauchi A (1994) Evolutionarily stable seasonal timing of univoltine and 675 bivoltine insects. In: Series Entomologica (ed. Danks HV), pp. 69-89.

676Jackson JK, Battle JM, White BP, et al. (2014) Cryptic biodiversity in streams: a comparison 677 of macroinvertebrate communities based on morphological and DNA barcode 678 identifications. Freshwater Science, 33, 312-324.

679Jombart T (2008) ADEGENET: a R package for the multivariate analysis of genetic markers. 680 Bioinformatics, 24, 1403-1405.

681Jombart T, Devillard S, Balloux F (2010) Discriminant analysis of principal components: a 682 new method for the analysis of genetically structured populations. BMC Genetics, 11, 68394.

684Jörger KM, Schrödl M (2013) How to describe a cryptic species? Practical challenges of 685 molecular taxonomy. Frontiers in Zoology, 10, 59.

686Keller I, Alexander JM, Holderegger R, Edwards PJ (2013) Widespread phenotypic and 687 genetic divergence along altitudinal gradients in animals. Journal of Evolutionary 688 Biology, 26, 2527-2543.

689Kiss B, Samu F (2005) Life history adaptation to changeable agricultural habitats: 690 Developmental plasticity leads to cohort splitting in an agrobiont wolf spider. 691 Environmental Entomology, 34, 619-626.

692Kivelä SM, Valimaki P, Gotthard K (2013) Seasonality maintains alternative life-history 693 phenotypes. Evolution, 67, 3145-3160.

694Knispel S, Sartori M, Brittain JE (2006) Egg development in the mayflies of a Swiss glacial 695 floodplain. Journal of the North American Benthological Society, 25, 430-443.

696Kukula K (1997) The life cycles of three species of Ephemeroptera in two streams in Poland. 697 Hydrobiologia, 353, 193-198.

698Landa V (1969) Jepice - Ephemeroptera in Fauna ČSSR Československá akademie věd, 699 Praha.

700Lavandier P (1982) Evidence of upstream migration by female adults of Baetis alpinus 701 (Ephemeroptera) at high altitude in the Pyrenees. Annales de Limnologie, 18, 55-60. 
702Lavandier P (1988) Semivoltinism in high mountain populations of Baetis alpinus Pictet. 703 (Ephemeroptera). Bulletin de la Société d'Histoire Naturelle de Toulouse, 124, 61-64.

704Lenfant P, Planes S (2002) Temporal genetic changes between cohorts in a natural population 705 of a marine fish, Diplodus sargus. Biological Journal of the Linnean Society, 76, 9-20.

706Leys M, Keller I, Räsänen K, Gattolliat J-L, Robinson CT (2016) Distribution and population 707 genetic variation of cryptic species of the Alpine mayfly Baetis alpinus 708 (Ephemeroptera: Baetidae) in the Central Alps. BMC Evolutionary Biology, 16, 77.

709Loiselle BA, Sork VL, Nason J, Graham C (1995) Spatial genetic structure of a tropical 710 understory shrub, Psychotria officinalis (Rubiaceae). American Journal of Botany, 82, 711 1420-1425.

712López-Rodríguez MJ, de Figueroa JMT, Alba-Tercedor J (2008) Life history and larval 713 feeding of some species of Ephemeroptera and Plecoptera (Insecta) in the Sierra 714 Nevada (Southern Iberian Peninsula). Hydrobiologia, 610, 277-295.

715Mac Arthur RH, Levins R (1964) Competition, habitat selection and character displacement 716 in a patchy environment. Proceedings of the National Academy of Sciences of the $717 \quad$ United States of America, 51, 1207-1210.

718Malard F, Tockner K, Ward JV (2000) Physico-chemical heterogeneity in a glacial riverscape. $719 \quad$ Landscape Ecology, 15, 679-695.

720Masaki S (1978) Seasonal and latitudinal adaptations in the life cycles of crickets. In: 721 Evolution of insect migration and diapause, pp. 72-100. Dingle, H., Springer-Verlag, 722 New York.

723Merilä J, Hendry AP (2014) Climate change, adaptation, and phenotypic plasticity: the 724 problem and the evidence. Evolutionary Applications, 7, 1-14.

725Montero-Pau J, Gómez A, Muñoz J (2008) Application of an inexpensive and high726 throughput genomic DNA extraction method for the molecular ecology of 727 zooplanktonic diapausing eggs. Limnology and Oceanography: Methods, 6, 218-222.

728Muir AP, Biek R, Thomas R, Mable BK (2014) Local adaptation with high gene flow: 729 temperature parameters drive adaptation to altitude in the common frog (Rana 730 temporaria). Molecular Ecology, 23, 561-574.

731Nylin S, Wickman PO, Wiklund C (1995) Life-cycle regulation and life history plasticity in 732 the speckled wood butterfly: are reaction norms predictable? Biological Journal of the 733 Linnean Society, 55, 143-157.

734Pante E, Puillandre N, Viricel A, et al. (2015) Species are hypotheses: avoid connectivity 735 assessments based on pillars of sand. Molecular Ecology, 24, 525-544.

736Pauls SU, Nowak C, Bálint M, Pfenninger M (2013) The impact of global climate change on 737 genetic diversity within populations and species. Molecular Ecology, 22, 925-946. 
738Peckarsky BL, Taylor BW, Caudill CC (2000) Hydrologic and behavioral constraints on 739 oviposition of stream insects: implications for adult dispersal. Oecologia, 125, 186740200.

741Pereira-da-Conceicoa LL, Price BW, Barber-James HM, et al. (2012) Cryptic variation in an 742 ecological indicator organism: mitochondrial and nuclear DNA sequence data confirm 743 distinct lineages of Baetis harrisoni Barnard (Ephemeroptera: Baetidae) in southern

744 Africa. BMC Evolutionary Biology, 12, 26.

745Pfennig KS, Pfennig DW (2009) Character displacement: ecological and reproductive 746 responses to a common evolutionary problem. Quarterly Review of Biology, 84, 253 $747 \quad 276$.

748Pfenninger M, Schwenk K (2007) Cryptic animal species are homogeneously distributed 749 among taxa and biogeographical regions. BMC Evolutionary Biology, 7, 121.

750Qvarnström A, Svedin N, Wiley C, Veen T, Gustafsson L (2005) Cross-fostering reveals 751 seasonal changes in the relative fitness of two competing species of flycatchers. 752 Biology Letters, 1, 68-71.

753Qvarnström A, Wiley C, Svedin N, Vallin N (2009) Life-history divergence facilitates 754 regional coexistence of competing Ficedula flycatchers. Ecology, 90, 1948-1957.

755R Core Team (2016) R: A language and environment for statistical computing. R Foundation 756 for Statistical Computing, Vienna, Austria.

757Robinson CT, Tonolla D, Imhof B, Vukelic R, Uehlinger U (2016) Flow intermittency, 758 physico-chemistry and function of headwater streams in an Alpine glacial catchment. 759 Aquatic Sciences, 78, 327-341.

760Roff D (1983) Phenological adaptation in a seasonal environment: a theoretical perspective. 761 In: Diapause and life cycle strategies in insects (eds. Brown VK, Hodek I), pp. 253 762 270. W. Junk Publishers, The Hague, Netherlands.

763Roff D (2002) Life history evolution Sinauer Associates, Sunderland, USA.

764Ryo M, Leys M, Robinson CT (2016) Technical note: Fourier approach for estimating the 765 thermal attributes of streams. Hydrology and Earth System Sciences, 20, 3411-3418.

766Sartori M, Landolt $\mathrm{P}$ (1999) Atlas de distribution des éphémères de Suisse (Insecta, 767 Ephemeroptera) SEG-CSCF, Neuchâtel, Switzerland.

768Scheffers BR, Joppa LN, Pimm SL, Laurance WF (2012) What we know and don't know 769 about Earth's missing biodiversity. Trends in Ecology \& Evolution, 27, 501-510.

770Scherrer SC, Appenzeller C, Laternser M (2004) Trends in Swiss Alpine snow days: The role 771 of local- and large-scale climate variability. Geophysical Research Letters, 31, 772 L13215.

773Schluter D (2001) The ecology of adaptative radiation Oxford University Press, Oxford, UK. 
774Schmidt SK, Hughes JM, Bunn SE (1995) Gene flow among conspecific populations of 775 Baetis sp. (Ephemeroptera): adult flight and larval drift. Journal of the North 776 American Benthological Society, 14, 147-157.

777Schneider CA, Rasband WS, Eliceiri KW (2012) NIH Image to ImageJ: 25 years of image $778 \quad$ analysis. Nature Methods, 9, 671-675.

779Seehausen O (2009) Speciation affects ecosystems. Nature, 458, 1122-1123.

780Sniegula S, Golab MJ, Drobniak SM, Johansson F (2016) Seasonal time constraints reduce 781 genetic variation in life-history traits along a latitudinal gradient. Journal of Animal $782 \quad$ Ecology, 85, 187-198.

783Stearns SC (1992) The evolution of life histories Oxford University Press, Oxford, UK.

784Stuart YE, Losos JB (2013) Ecological character displacement: glass half full or half empty? 785 Trends in Ecology \& Evolution, 28, 402 - 408.

786Studemann D, Landolt P, Sartori M, Hefti D, Tomka I (1992) Ephemeroptera. Insecta 787 helvetica, Fauna 9 Imprimerie Mauron, Tinguely and Lachat SA, Fribourg, $788 \quad$ Switzerland.

789Sweeney BW (1978) Bioenergetic and developmental response of a mayfly to thermal $790 \quad$ variation. Limnology and Oceanography, 23, 461-477.

791Tauber CA, Tauber MJ (1981) Insect seasonal cycles: genetics and evolution. Annual Review 792 of Ecology and Systematics, 12, 281-308.

793Thomas AGB (1975) Ephéméroptères du Sud-Ouest de la France. I : migration d'imagos à 794 haute altitude. Annales de Limnologie, 11, 47-66.

795Tockner K, Malard F, Burgherr P, et al. (1997) Physico-chemical characterization of channel 796 types in a glacial floodplain ecosystem (Val Roseg, Switzerland). Archiv Für 797 Hydrobiologie, 140, 433-463.

798Uehlinger U (1991) Spatial and temporal variability of the periphyton biomass in a prealpine 799 river (Necker, Switzerland). Archiv Für Hydrobiologie, 123, 219-237.

800Uehlinger U, Robinson CT, Hieber M, Zah R (2010) The physico-chemical habitat template 801 for periphyton in alpine glacial streams under a changing climate. Hydrobiologia, 657, 802 107-121.

803Verrier ML (1956) Biologie des éphémères Collection Armand Colin, Paris, France.

804Ward JV, Stanford JA (1982) Thermal responses in the evolutionary ecology of aquatic 805 insects. Annual Review of Entomology, 27, 97-117.

806Weir BS, Cockerham CC (1984) Estimating F-statistics for the analysis of population 807 structure. Evolution, 38, 1358-1370.

808Wilbur HM, Rudolf VHW (2006) Life-history evolution in uncertain environments: Bet809 hedging in time. American Naturalist, 168, 398-411. 
810Williams HC, Ormerod SJ, Bruford MW (2006) Molecular systematics and phylogeography 811 of the cryptic species complex Baetis rhodani (Ephemeroptera, Baetidae). Molecular $812 \quad$ Phylogenetics and Evolution, 40, 370-382.

813

814DATA ACCESSIBILITY

815Nuclear microsatellite data, larval size measurements and environmental data (temperature, 816periphyon and water chemistry) are available from the Dryad Digital Repository: 817 $\underline{\text { http://dx.doi.org/10.5061/dryad.kt364 }}$

\section{AUTHOR CONTRIBUTIONS}

819ML, IK, CTR and KR conceived and designed the study. ML and CTR performed field 820sampling. ML carried out part of the laboratory work, analyzed the data and prepared the first 821 manuscript draft and all authors contributed substantially to the writing of the manuscript. All 822authors read and approved the final manuscript.

823 


\section{TABLES}

825Table 1. Hierarchical variance partitioning and F-statistics of population genetic 826differentiation within lineage $A$ (there was insufficient data for lineage $B$ ). Analyses were 827performed separately within the Lötschental and Roseg basins. Significant values $(P<0.05)$ 828are shown in bold.

Variance components

\begin{tabular}{lccccc}
\hline & $\begin{array}{c}\text { Strea } \\
\mathrm{m}\end{array}$ & Site & Cohort & Individual & Error \\
\hline Lötschental & 0.160 & 0.020 & 0.100 & 0.650 & 6.900 \\
Roseg & 0.110 & 0.020 & 0.110 & 0.680 & 6.990 \\
\hline
\end{tabular}

Hierarchical $\boldsymbol{F}$-statistics

\begin{tabular}{lcccc}
\hline & $F_{\text {StREAM-TOTAL }}$ & $F_{\text {SITE-STREAM }}$ & $F_{\text {COHORT-SITE }}$ & $F_{\text {IND-COHORT }}$ \\
\hline Lötschental & 0.020 & 0.003 & $\mathbf{0 . 0 1 3}$ & 0.086 \\
Roseg & 0.014 & 0.002 & $\mathbf{0 . 0 1 4}$ & 0.088 \\
\hline
\end{tabular}

\section{9}

830 
831Table 2. Correlation coefficients of Partial Mantel tests i) between individual pairwise genetic 832distances (G) (Cavalli \& Sforza 1969) and temporal distances (T) (i.e. Matrix pair G x T), 833when cohort type (C) was controlled for, and ii) between genetic distances and cohort type

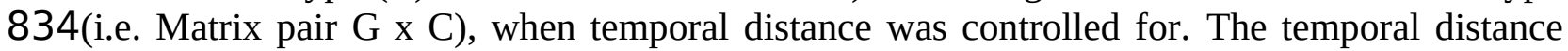
835matrix is expressed as cohort number for temporally ordered cohorts within each study site 836(see Figure 2 for details). The cohort type matrix indicates which of the three cohort 837categories a pair of individuals belongs to (i.e. summer-summer, winter-winter or winter838 summer cohort pairs). Significant values $(P<0.05)$ are indicated in bold.

\begin{tabular}{ccccc}
\hline Site & $\begin{array}{c}\text { Matrix pair } \\
\text { tested }\end{array}$ & $\begin{array}{c}\text { Matrix } \\
\text { controlled }\end{array}$ & $r$ & $P$ \\
\hline LM3 & $\mathrm{G} \times \mathrm{T}$ & $\mathrm{C}$ & -0.018 & 0.271 \\
LM3 & $\mathrm{G} \times \mathrm{C}$ & $\mathrm{T}$ & 0.226 & $\mathbf{0 . 0 0 2}$ \\
LM5 & $\mathrm{G} \times \mathrm{T}$ & $\mathrm{C}$ & -0.051 & 0.064 \\
LM5 & $\mathrm{G} \times \mathrm{C}$ & $\mathrm{T}$ & 0.156 & $\mathbf{0 . 0 0 5}$ \\
LT2 & $\mathrm{G} \times \mathrm{T}$ & $\mathrm{C}$ & 0.059 & 0.098 \\
LT2 & $\mathrm{G} \times \mathrm{C}$ & $\mathrm{T}$ & 0.173 & $\mathbf{0 . 0 1 2}$ \\
LT4 & $\mathrm{G} \times \mathrm{T}$ & $\mathrm{C}$ & 0.180 & $\mathbf{0 . 0 0 1}$ \\
LT4 & $\mathrm{G} \times \mathrm{C}$ & $\mathrm{T}$ & 0.318 & $\mathbf{0 . 0 0 1}$ \\
$R M 2$ & $\mathrm{G} \times \mathrm{T}$ & $\mathrm{C}$ & 0.028 & 0.134 \\
$R M 2$ & $\mathrm{G} \times \mathrm{C}$ & $\mathrm{T}$ & 0.189 & $\mathbf{0 . 0 0 0}$ \\
$R M 3$ & $\mathrm{G} \times \mathrm{T}$ & $\mathrm{C}$ & 0.042 & 0.150 \\
$R M 3$ & $\mathrm{G} \times \mathrm{C}$ & $\mathrm{T}$ & 0.006 & 0.408 \\
$R T 2$ & $\mathrm{G} \times \mathrm{T}$ & $\mathrm{C}$ & -0.001 & 0.495 \\
$R T 2$ & $\mathrm{G} \times \mathrm{C}$ & $\mathrm{T}$ & 0.242 & $\mathbf{0 . 0 0 0}$ \\
$R T 4$ & $\mathrm{G} \times \mathrm{T}$ & $\mathrm{C}$ & 0.217 & $\mathbf{0 . 0 0 0}$ \\
$R T 4$ & $\mathrm{G} \times \mathrm{C}$ & $\mathrm{T}$ & -0.004 & 0.487 \\
\hline
\end{tabular}

839 


\section{FIGURE LEGENDS}

841Figure 1. (a) General location of study areas within Europe and (b) the two glacierized study 842basins (indicated by boxes) in Switzerland. (c) Sampling sites are visualized at the basin scale 843and labeled as in Leys et al. (2016). Main glacier-fed channel sites and tributaries are 844 indicated by white and dark grey, respectively. Dotted arrows show river flow direction. Sites 845 for which genetic data were available are marked with an asterisk.

846Figure 2. B. alpinus cohorts determined by Gaussian mixture models of monthly larval size 847density distributions (only for sites for which genetic data were available. Size based cohorts 848for all remaining sites are given in Figure S1). Cohort identification was based on models of 849mixture components (see material and methods for details). A given cohort type (winter 850 cohorts $a$ and $b$ and summer cohorts $c$ and $d$ ) is depicted by the same color within and 851 between seasonal cycles. The numbers $(1,2,3)$ distinguish cohorts across two seasonal cycles 852(e.g., $a 1$ and $a 2$ represent the first winter cohorts in 2012 and 2013, and b1 and b2 the second 853 winter cohorts, respectively).

854Figure 3. Scheme of the hierarchical levels included in the hierarchical analysis of population 855genetic differentiation within a lineage (see Table 1 for statistical analyses).

856Figure 4. Genetic assignment of 789 individuals to B. alpinus cryptic lineages based on 10 857microsatellite markers in two glacierized basins of the Swiss Alps. (a) Individual assignment 858to $A$ (blue) and $B$ lineages (green) using DAPC. The x-axis shows the values of the first 859discriminant function for each individual (vertical bars) and the y-axis indicates the smoothed 860density of observations. (b) Violin plots of spatio-temporal distribution of B. alpinus lineages $861 A$ and $B$ in Lötschental and Roseg in 2012 (upper panels) and 2013 (lower panels). The few $862 B$. melanonyx individuals identified based on genetic data are also indicated. Each colored 863symbol corresponds to an individual (Blue: lineage $A$; Green: lineage $B$; Orange: 864B. melanonyx). Each violin plot represents the larval size distribution at the morphospecies 865level. Larval body length $(\mathrm{mm})$ is indicated on the y-axis. Dots and triangles indicate early to 866intermediate larval stages and last-instars, respectively. For Roseg tributary RT2 (in 2013), the 867presence of egg clutches is indicated for each lineage by filled squares above the panel.

868Figure 5. Genetic affinities between cohorts within each B. alpinus lineage visualized by 869discriminant analysis of principal components (DAPC) on 10 microsatellite markers in (a) 870lineage $A$ in Lötschental, (b) lineage $A$ in Roseg, and (c) lineage $B$ in Roseg. Scatterplots 871show the first two principal components of the DAPC. Eigenvalues corresponding to the 872represented components are filled in black in the right insert. The number of principal 873 components retained and their cumulative variance explained are highlighted in black in the 874left-insert. The cohorts $(a, b, c, d)$ within each annual cycle are depicted by colors (as in 875Figure 2). 


\section{Figure 1.}

878a.

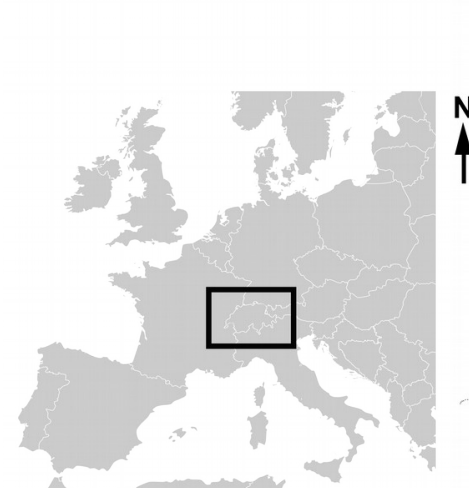

c. Lötschental Lang glacier

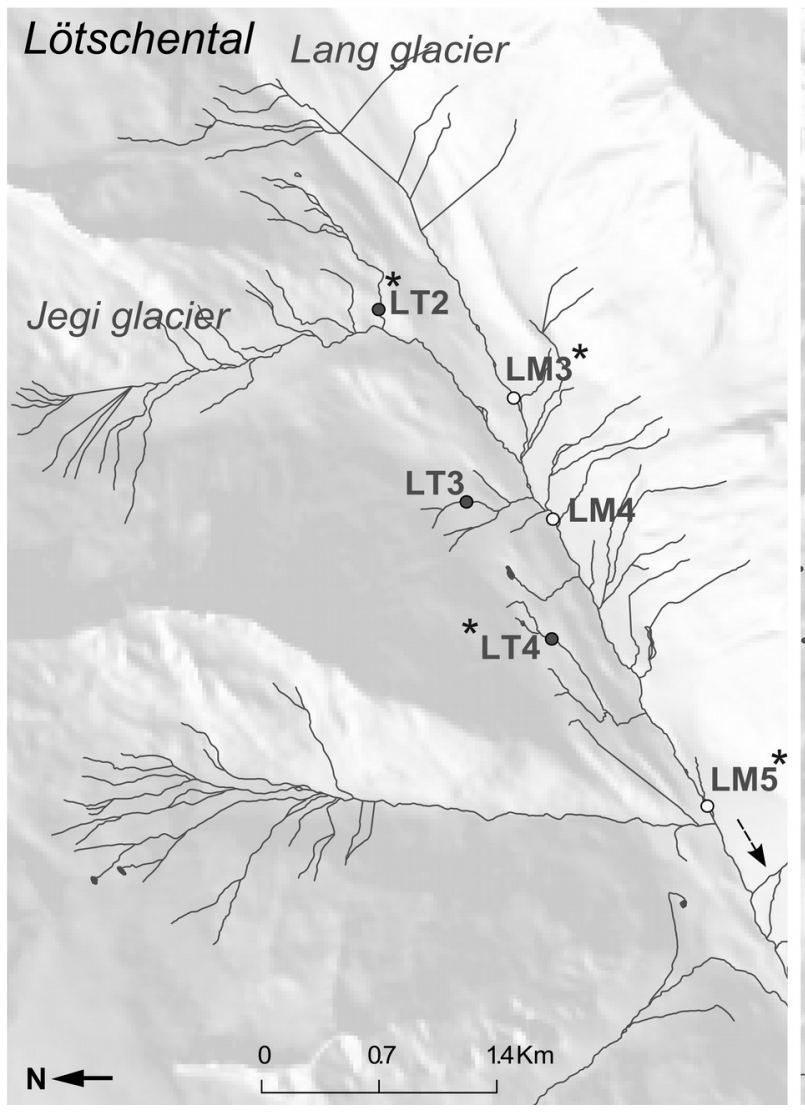

b.

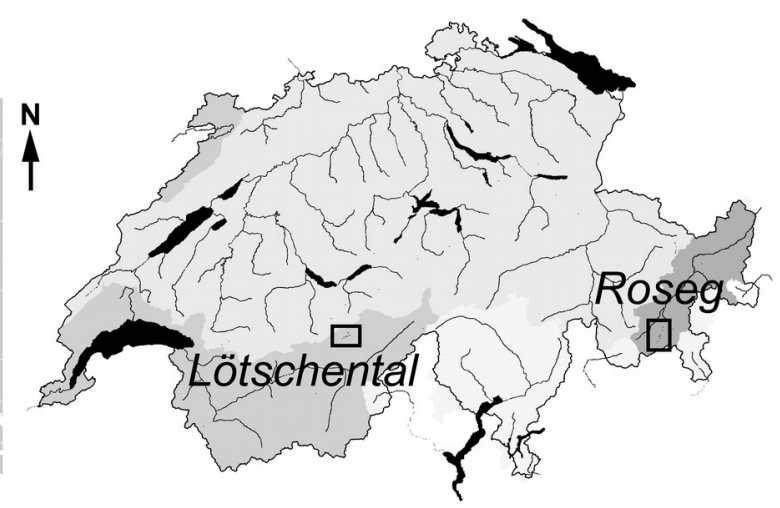

Roseg

Tschierva glacier

Roseg glaciey

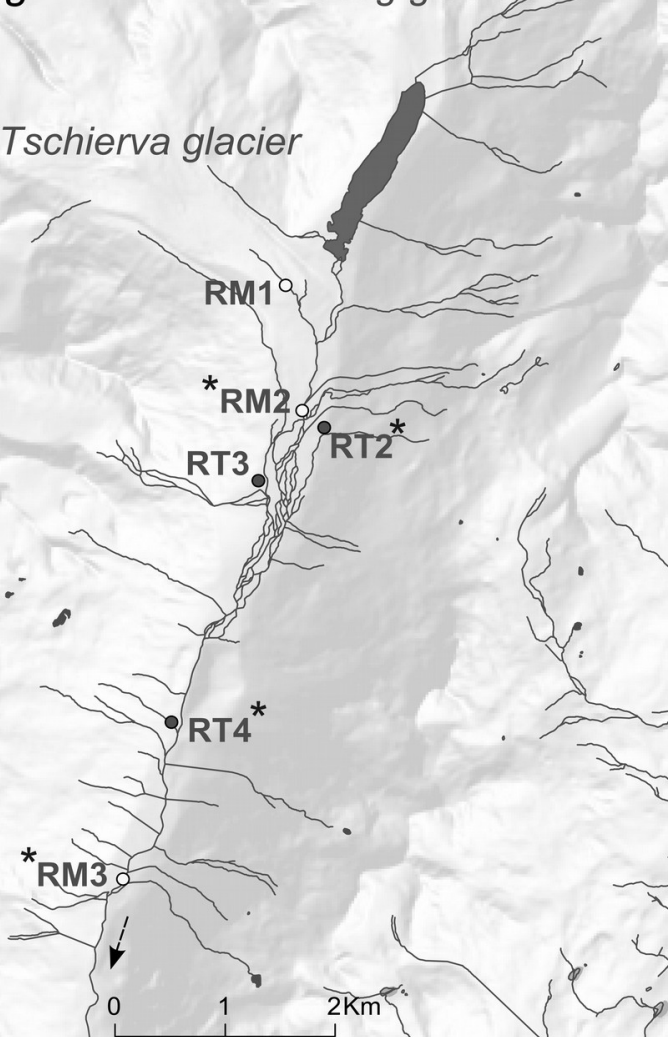

880 


\section{Figure 2.}
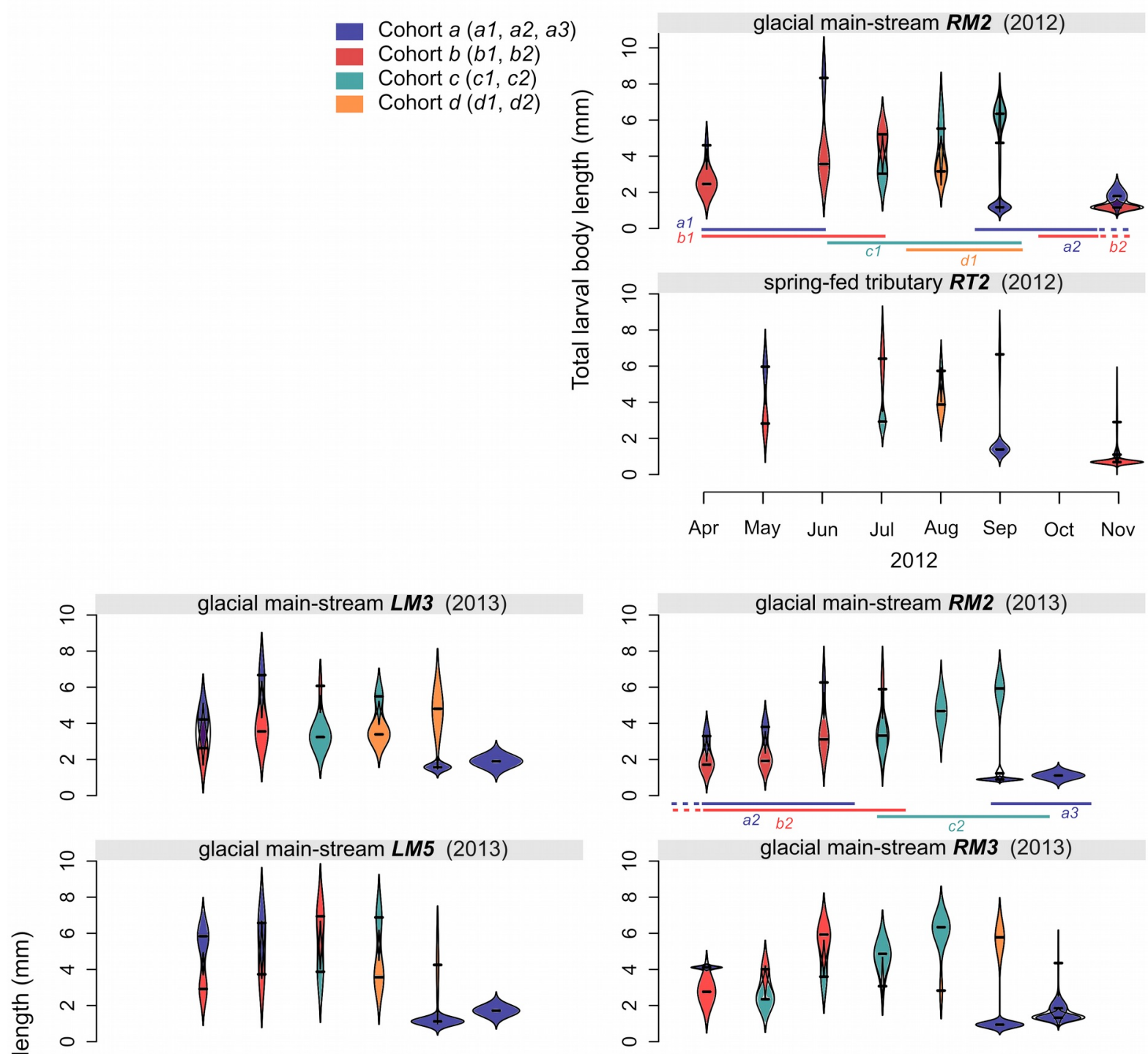

$\left.\begin{array}{ll}\frac{0}{2} & 0 \\ \frac{\lambda}{0} & \\ \frac{0}{\overline{0}} & 0 \\ \frac{\pi}{2} & \infty \\ \frac{0}{\pi} & 0 \\ \frac{\pi}{0} & + \\ \frac{1}{0} & \cdots \\ & 0\end{array}\right]$

spring-fed tributary LT2 (2013)
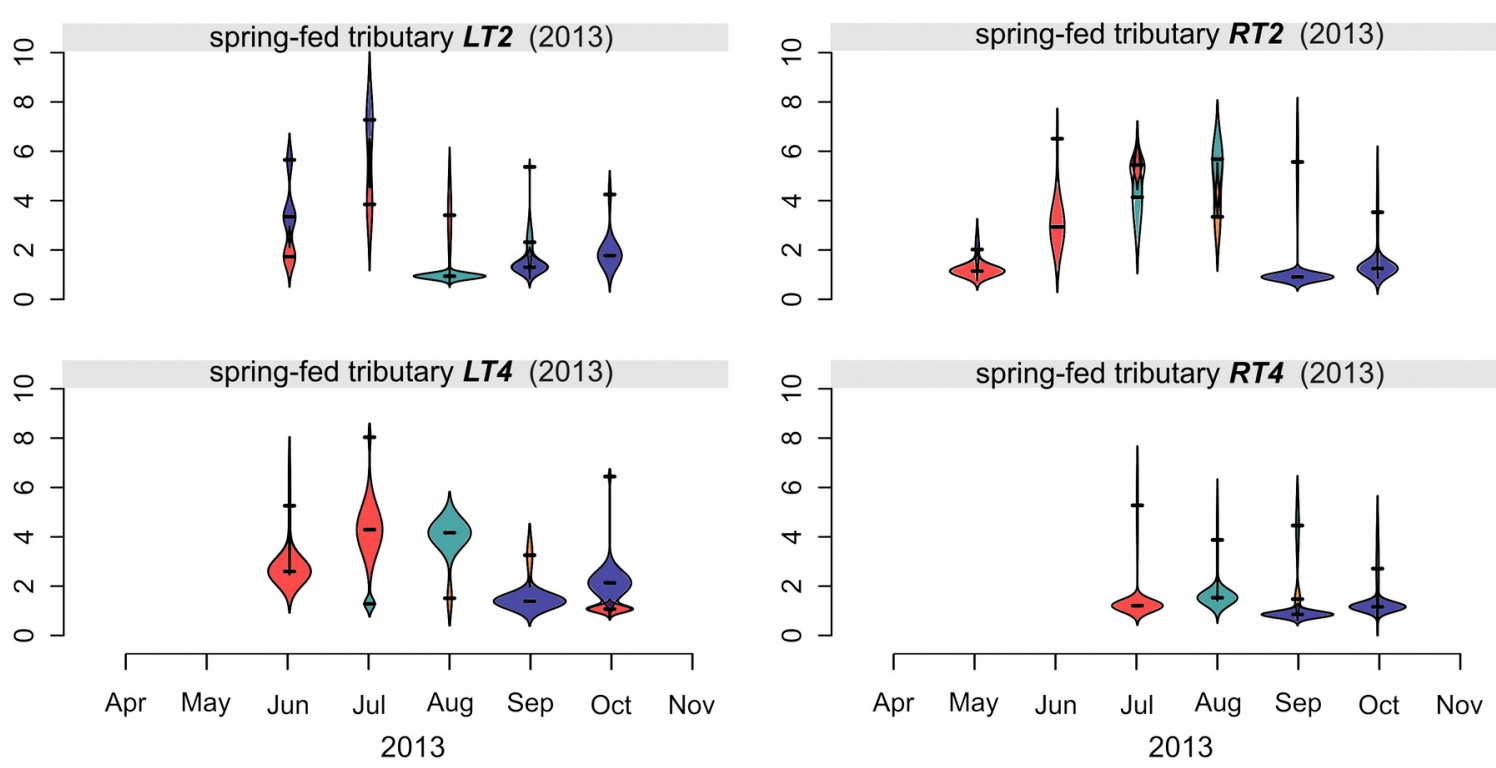


\section{Figure 3.}

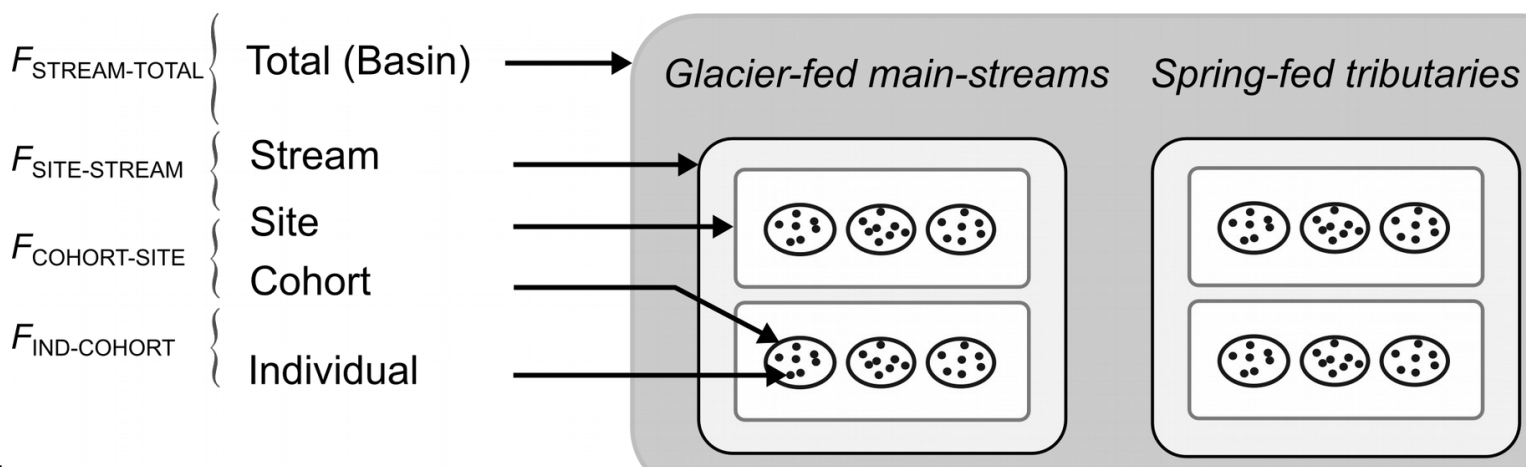

885

886 


\section{Figure 4.}

888a.
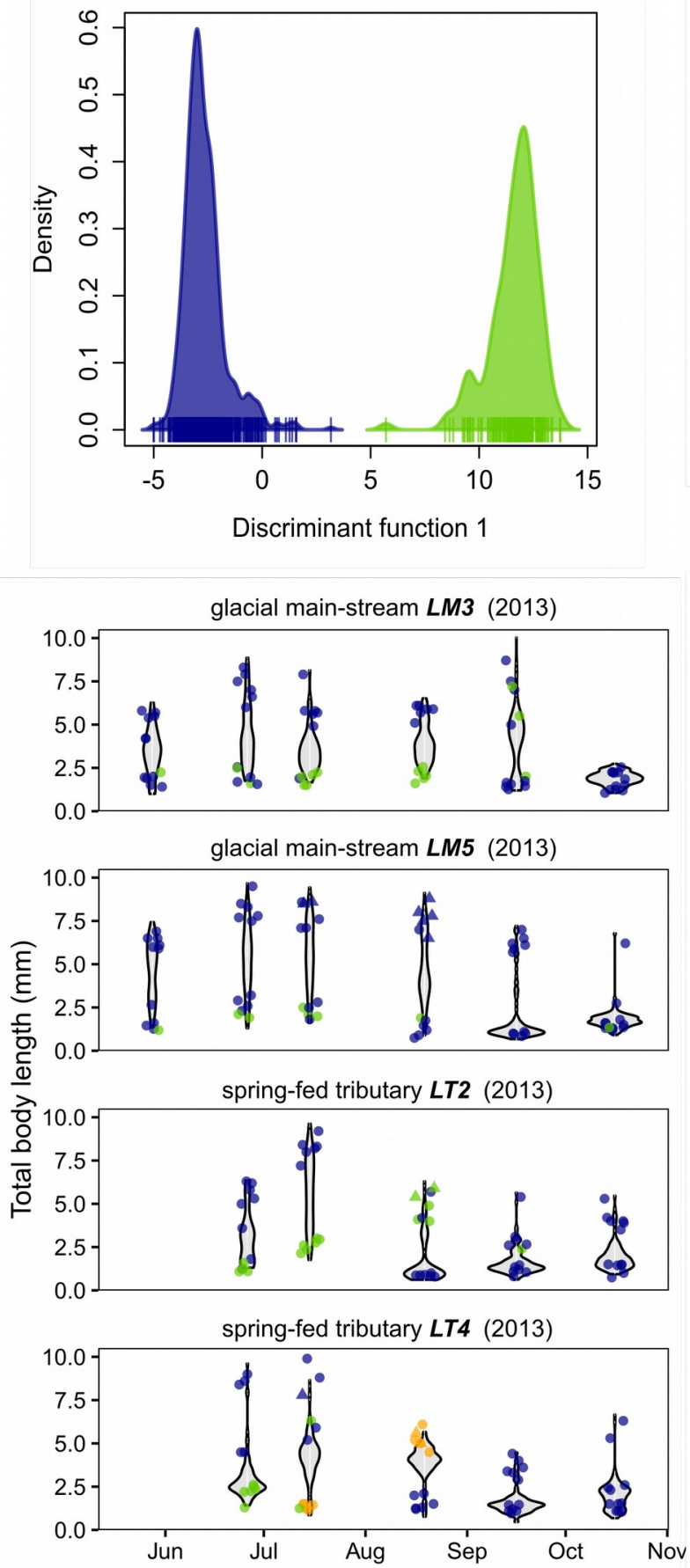

b.
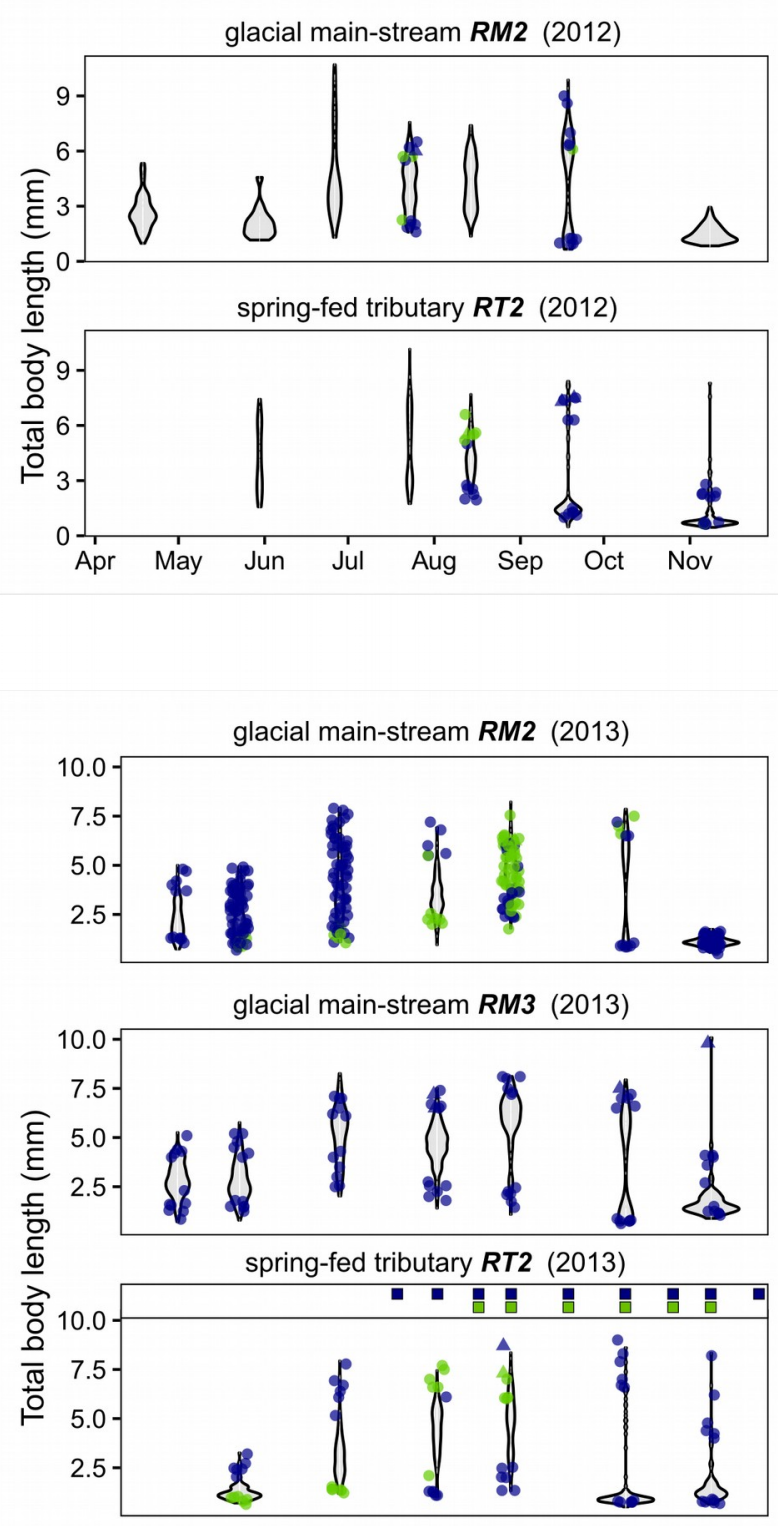

spring-fed tributary RT4 (2013)

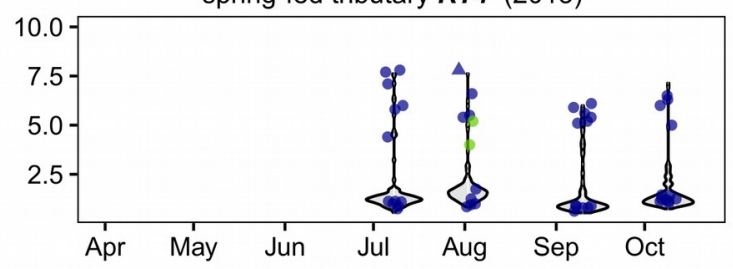




\section{Figure 5.}

892
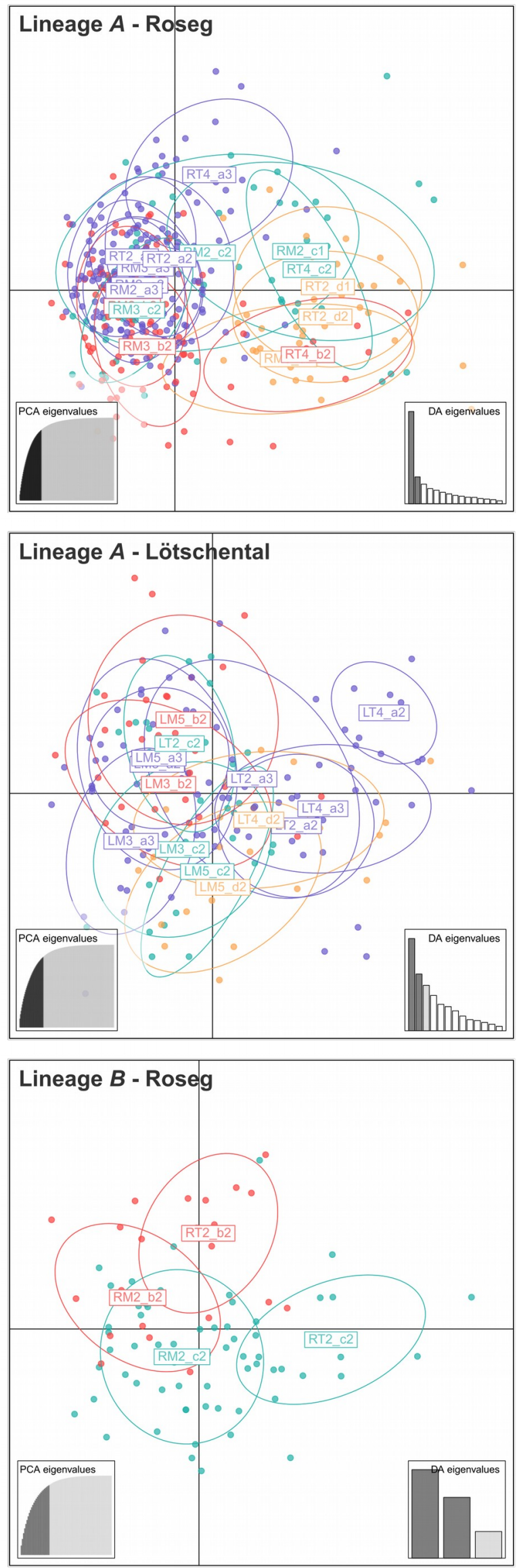